\title{
A TENACIOUS BASE ISOLATION SYSTEM USING ROUND STEEL BARS
}

\author{
R.G. Tyler*
}

\begin{abstract}
The tenacity of reinforving bars in resisting earthquake loading, after concrete had spalled away around them, suggests that round bars can be used to dissipate earthquake energy in base isolated buildings, provided a bow is introduced in the bars to allow them to extend as the building deflects on its bearings. Dynamic tests are described which enable a design method for such a system to be evolved. The method has the advantage of simplicity in that round bars available in normal engineering practice can be utilised, while a tensile capacity is introduced between the structure and the foundation which enables the system to progressively lock up under disaster conditions.
\end{abstract}

\section{INTRODUCTION}

The tenacity of rcinforcing bars in resisting earthquake loading after the concrete has spalled away around them has been demonstrated in many instances of failed elements in buildings. Failures in columns of the type shown in plate 1 suggest that if the weight of a building is supported on laminated rubber bearings, as has already been proposed for base isolation methods, and which offers significant advantage for $, 3,3$, then bent round bars may perform a function in supplying both damping and a tenacious connection between the foundation and the base of the building. Such a design would have an advantage in its simplicity.

Tests were carried out at the Physics and Engineering Laboratory with a view to developing such a system. The results of the tests, and extrapolations for design purposes, are given in this paper.

\section{BASE ISOLATION METHOD}

The method proposed is illustrated in Fig. 1. Building columns are mounted on rubber bearings and round steel bars having a semi-circular bent in their length are concreted into the foundation slab, in the same way as starter bars, and, with the rubber bearings in position, their tops are concreted into the lower floor slab or beam of the building. A large number of smaller diameter bars operating over a short length or a small number of larger diameter bars operating on a longer length will perform the same function for the chosen movement related to the design earthquake, except that the shorter the bars the sooner a complete lock-up is induced as the length available for straightening is reduced. For reasons of symmetry it would be expected that $50 \%$ of the bars would be distributed with the bends in a single plane somewhat as shown in $\mathrm{Fig.} 1$, and the remaining $50 \%$ in the direction at right angles.

* Physics and Engineering Labcratory, Department of Scientific and Industrial Research, Gracefield, Wellington.
Following the principles of base isolation previously set out, for a horizontal damping force per bar, $Q_{d}$, as defined by the bilinear loop for the bar (Fig. 2), the sum of all such forces arising from all the bars would be designed to about $5 \%$ of the building weight. A small amount of damping is also found in the laminated rubber bearings (4).

The possible effects of movements arising from concrete shrinkage in the horizontal plane on both the rubber bearings and the bars cannot be ignored. The final concreting of one end of the bars should be left as late as possible in the construction and, at the same time, the rubber bearings could be re-positioned if necessary by jacking at each bearing.

\section{DETAILS OF THE BARS TESTED}

The shape of the bars tested is shown in Fig. 3 and Plates 2 and 3 . For a dimension $L$ between the fixities a semicircular length of radius $\mathrm{L} / 4$ provides for a length change when the building moves horizontally under earthquake attack. The exact shape is probably not critical, provided the bend will allow for the length change.

For the tests I was $476 \mathrm{~mm}$, with a variation of diameters of steel bar from $12 \mathrm{~mm}$ to $38 \mathrm{~mm}$ to ensure a range of strain conditions. Fixity was provided by making the bar a push fit in steel mounting plates and welding at the top and bottom away from the highly strained zone.

The bars were bent to shape after heating to a red heat. Bright steel bars of commercial quality were used (not free cutting), as they were readily available; black steel bars to BS 4360/43A, having the same chemically composition, could equally well have been used. After bending the bars were stress relieved for 5 hours at $620^{\circ} \mathrm{C}$ to restore the yield point. A more complicated shape was tried involving a complete turn of steel, as shown in the photograph, (Plate 3) but although the results were similar this shape was abandoned 
because of the extra difficulty in manufacture.

For small horizontal deflections the bar behaves as a double cantilever with plastic hinges developing at the top and bottom fixities. If $Q$ is the horizontal shear force to generate this plasticity, then the plastic moment $=\frac{Q L}{2}$. Under extreme horizontal deflections (Fig. 4), the induced length change gives rise to a force $F$. Evidently the bar will extend when a plastic moment develops at the centre $=\mathrm{FL} / 4$, i.e. for the chosen shape. $F=2 Q$. For horizontal loading in the direction at right angles to the bend, torsion develops at its centre but this is not sufficient to cause yielding prior to yield deveioping at the fixities.

It is evident that the bar will resist uplift should this occur and could be used at the corners of buildings to assist in stability. The upward force $F$ will

initially rise to the value required to cause plasticity at the centre of the bow, but later, in the event of severe uplift. will be the tensile capacity of the bar. The anchorage required will depend on the condition the designer wishes to allow for.

\section{TEST PROCEDURE}

Initial tests were carried out utilising the horizontal movement controlled by a steel plate sandwiched between rubber bearings, following tests on these bearings (4). This gave reasonable fatigue lives for $25 \mathrm{~mm}$ and $38 \mathrm{~mm}$ bars, whereupon a travelling platform was connected to the test drive, which enabled load-displacement hysteresis loops to be obtained for the bent bar on its own, without the addition of the effects of elasticity in the rubber bearings. For all tests the stroke was about $150 \mathrm{~mm}$ and the frequencies of loading were in the range 0.2 to $0.9 \mathrm{~Hz}$. Other tests have shown that, for steel, the number of cycies to failure is not greatly influenced by the rate of loading. One of the $25 \mathrm{~mm}$ bars was instrumented with two pairs of strain gauges (Plate 2) located as near as possible to the fixities. The strain range was recorded statically with the drive in extreme positions. Another bar was fitted with nylon inserts at the fixities in an attempt to extend its zone of plastic yield but the fatigue life was not improved (Table 1 ).

\section{RESULTS}

All the bars failed at one or other of the fixity points (Plate 3) with heating up at those points and little heating elsewhere. Typical hysteresis loops obtained in the tests are given in Fig. 5. Bilinear loops were superimposed in the experimental loops as indicated in the representative loop F'ig. 2. The forces $Q_{d}$ and Qmax were scaled from the loops and are given in Table 1, together with the number of cycles to failure from the load-time curves. A representative value for the slope $\mathrm{K}_{\mathrm{d}} / \mathrm{Q}_{\mathrm{d}}$ (Fig. 2) was $1 / 0.1 \mathrm{~T}$ i.e. about $70 \mathrm{~m}^{-1}$ for $\mathrm{T}=150 \mathrm{~mm}$. Values for the more important slope $\mathrm{k}_{\mathrm{d}} / \mathrm{Qd}_{\mathrm{d}}$ are given in Table $\mathrm{l}$ and are shown plotted in Fig. 6, together with values obtained from tests on taper cantilver dampers. At a strain range of $6 \%$ the mean value of $k_{d} / Q_{d}$ is seen to be approximately
$5 m^{-1}$.

From the forces $Q d$ the plastic stress $f_{p}$ was calculated using the assumption made in static design, viz that, within the section $f_{p}$ has a constant value right up to the neutral axis, tensile on one side and compressive on the other.

$$
\text { Evidently } \frac{Q_{d}}{2}=f_{p} K
$$

where $\mathrm{K}=$ the plastic modulus

$$
=\frac{4}{3} R^{3} \text { for a round bar }
$$

and $L=476 \mathrm{~mm}$ for the tests

i.e. $E_{p}=\frac{Q_{d} L}{2 K}$

The value of $f_{p}$ is seen to increase as the size of the bar, and consequently the strain level, increases; ultimately it is the value which is obtained when there is only one cycle to failure. The effect is normally shown up in testing by increasing the cyclic strain progressively during a single test, when a family of loops is obtained (Fig. 7).

Values of $f_{\mathrm{p}}$ were plotted against strain range in Fig. 8 together with results from other tests on energy absorbers. This graph, although only approximate, enables results to be extrapolated in determining dimensions for any size of energy absorber.

In the test with strain gauges, using a $25.4 \mathrm{~mm}$ bar, the strain ranges recorded statically for the full $150 \mathrm{~mm}$ travel were $6.76,5.82,6.02$ and 6.73 per cent respectively giving a mean value of 6.33 . Strain values for other diameters were estimated by taking strain as proportional to diameter for the fixed travel of the tests and are given in Table 1 .

Values of number of cycles to failure are plotted against strain range in $\mathrm{Fig} .9$. superimposed on the graph is the curve previously derived for the low-cycle fatigue relationship for mild steel in bending (7). The fatigue lives of the bent bars are seen to be a little shorter than the values indicated by this curve, probably because the strains were not measured at the point of failure at the face of the fixity.

\section{EXTRAPOLATION OF RESULTS TO TYPICAL DESIGN CONDITIONS}

The test results may be scaled to suit any depth of crawl space between the lower floor of a building and the foundation. For the test conditions, a strain of $6.3 \%$ was recorded for a length between fixities of $476 \mathrm{~mm}$, a diameter of $25.4 \mathrm{~mm}$ and a travel of $150 \mathrm{~mm}$. For general values of these quantities, S, L, D and $T$ respectively, in $\mathrm{mm}$, evidently:

$S=0.063 \times \frac{D}{25.4} \times \frac{476^{2}}{L^{2}} \times \frac{T}{150}$

i.e. $L^{2}=3.75 \mathrm{DT} / \mathrm{s} \mathrm{mm}^{2}$

In the graph (Fig. 10) the lengths L are plotted for a range of bar diameters $D$ and strain ranges $S$ for a stroke $T$ of $150 \mathrm{~mm}$, this being an accepted design value for a moderate to severe earthquake. 
The load $Q_{d}$ carried by a bar of diameter $D$ and length $L$, determined from equation (2), may be obtained by use of the plastic stress $f_{p}$ obtained from Fig. 8 for the design strain range. From equation (1)

$Q_{\mathrm{d}}=\frac{2 \mathrm{f}_{\mathrm{p}} \mathrm{K}}{\mathrm{L}}$

The design strain range itself depends on the desired number of cycles to failure (as given by the graph Fig. 9). A life of 100 cycles has, up to now, been considered acceptable, but more research needs to be done on this topic, particularly as testing so far has been done in a single direction for a single value of stroke, whereas an earthquake will move the building in any horizontal direction with a variety of magnitudes of stroke.

In calculating the effect of this base isolation method on a structure it is suggested that the values of $\mathrm{K}_{\mathrm{d}} / \mathrm{Q}_{\mathrm{d}}$ and $\mathrm{kd} / \mathrm{Q}_{\mathrm{d}}$ for the bilinear loop be taken as $70 \mathrm{~m}^{-1}$ and $5 \mathrm{~m}^{-1}$ respectively with adjustments to $\mathrm{k}_{\mathrm{d}} / \mathrm{Qd}_{\mathrm{d}}$ depending on the strain level (Fig. $6)$.

The nearer the steel is worked to failure the less expensive the system in that the weight of steel is reduced. On the other hand, the permissible strain range may also depend on the deflection at first yield of the bars, as normal windstorms should not carry the bars into yield.

Following normal elastic design, the bars will begin to yield at a horizontal load Q' (Fig. 2) such that

$\frac{Q^{\prime} L}{2}=f_{y} Z$

i.e. $Q^{\prime}=2 \mathrm{f}_{\mathrm{Y}} \mathrm{Z} / \mathrm{L}$

where $\mathrm{F}_{\mathrm{y}}=$ yield stress obtained by static

$=275 \mathrm{MN} / \mathrm{m}^{2}$ approx

$\mathrm{Z}=$ section modulus $=\pi \mathrm{D}^{3} / 32$

The associated deflection $\Delta$ prior to yield is given by

$\Delta=Q^{\prime} L^{3} / 12 \mathrm{EI}$

where $\mathrm{E}=$ Young's modulus

$=200 \mathrm{GN} / \mathrm{m}^{2}$

$I=$ second moment of area

$=D^{4} / 64$

The load on the building to cause first yield of the bars is obtained by adding the load in the rubber bearings to the value of $Q^{\prime}$ for the deflection $\Delta$.

\section{POSSIBILITY OF EMBRITTLEMENT}

In view of the cases of age-embrittlement of reinforcing bars that have been reported in the literature $(6)$, mainly in sharp bends in the crimped type of bar, it is suggested that only plain round bars be employed for this application, using steel of known ductility, having a chemical composition to BS $4360 / 43 \mathrm{~A}$ or equivalent. For the present an approved stress relieving technique should be carried out after bending, particularly if the bars are bent cold. Later tests with accelerated ageing may establish that stress relief is not necessary for particular steels.

Tests already reported on a double cantilever energy absorber, which had been subjected to stress relieving treatment, showed no sign of embrittlement during intermittent testing over a period of two months at a strain range of $2 \%(7)$. It is likely therefore that embrittlement will not develop during the period of a single major earthquake and its after-shocks. If tests do not eliminate the possibility of a slow development afterwards it is suggested that for buildings in higher risk areas expanded polystyrene plugs be left in the concrete in order to enable a duplicate set of bars to be fitted at a later date, if necessary. Alternatively, stress relief of overstrained bars may be carried out in-situ by means of induction coils fitted temporarily around the bars.

The problem of the age-embrittlement of steel is not confined to the use of bars in a base isolation system, as normal reinforcing bars are usually bent cold over quite sharp radii during the normal construction process and may therefore be embrittled for most of their life in the building.

In addition, their mode in the ductile dissipation of energy at the joints of a conventional structural frame, when strain ranges up to about $2 \%$ may be induced, may cause brittleness following a major earthquake.

It may be argued that rectifiable damage in a base isolation system is preferable to severe structural damage, and possible embrittlement of the steel, in a conventionally designed building, where the steel cannot be replaced.

\section{CONCLUSIONS}

The use of bowed steel bars in conjunction with rubber bearings in a base isolation system offers a simple means of dissipation of earthquake energy in that round bars available in normal engineering practice, can be utilised; a tensile capacity is introduced between the structure and the foundation which causes the system to progressively lock up under disaster conditions as deflections increase.

\section{REFERENCES}

1. Skinner, R. I., Beck, J. I. and Bycroft, G. N., "A Practical System for Isolating Structures from Earthquake Attack". Earthq. Eng. and Struct. Dyn. 3, p297-309, 1975 .

2. Priestley, M. J. N., Crosbie, R. L. and Carr, A. J., "Seismic Forces in BaseIsolated Masonry Structures". Bull. N.z. Nat. Soc. Earthq. Eng. 10, No. 2, June, 1977.

3. Lee, D. M. and Medland I. C., "Base Isolation for Earthquake Protection of Multi-storey Shear structures". Proc. of the Sixth Aust. Conf. Mech. Str. and Mat., Christchurch, August 1977. 
4. Tyler, R. G., "Dynamic Tests on

Laminated Rubber Bearings". Bull.N.Z. Nat. Soc. for Earthq. Eng. 10, No. 3, September, 1977.

5. Tyler, R. G., "The Design of Steel Taper Cantilever Energy Absorbers"

(To be Published.)

6. Erasmus, L. A. and Pussegoda, L. N.,

"Strain Age Embrittlement of Reinforcing

Steels". N.Z. Engineering, 32, No. 8, August 1978 .

7. Tyler, R. G., "Testing of Dampers for the Base Isolation of a Proposed 4-Storey Building Against Earthquake Attack",

Proc. of the Sixth Aust. Conf. Mech.

Str. and Mat., Christchurch, Aug. 1977.

Paper received 3 October, 1978.

\section{APPENDIX}

\section{Design Example}

In a scheme for base isolation using laminated rubber bearings it is desired to fit round bars over a crawl space depth of $1 . \operatorname{lm}$.

The desired life is 80 cycles at an amplitude of $\pm 75 \mathrm{~mm}$ for uniaxial horizontal loading during a moderate to severe earthquake.

The building is provided with stops allowing $\pm 150 \mathrm{~mm}$ of movement under disaster conditions.

It is required to find the size and number of bars. The load per bearing is $2,000 \mathrm{kN}$
From the graph, Fig. 9 the strain range associated with a life of 80 cycles is about 6\%. The diameter of bar associated with this strain is about 0.13 metres (Fig. 10) for $L=1.1 \mathrm{~m}$. This diameter is outside the range of the graph (Fig. 11) giving the $Q_{0}$ value, but from equation (3) $Q_{d}=287 \mathrm{kN}$ for $f_{p}=370 \mathrm{MN} / \mathrm{m}^{2}$, associated with a strain range of $6 \%$ (Fig. 8).

This is an excessive shear load to be concentrated at a single point and only about one bar would be required per 3 bearings for the required shear load of $2000 \mathrm{x} 0.05$ $=100 \mathrm{kN}$ per bearing.

If the bar size is reduced to $75 \mathrm{~mm}$ then the strain range will be $3.5 \%$ (Fig. 10 and equation 2), for which the load 0 is $33 \mathrm{kN}$ (Fig. 11 and equation 4), when $f_{p}=255 \mathrm{MN} / \mathrm{m}^{2}$ associated with the strain range of $3 \%$ (Fig. 8). This would give about 3 bars per bearing.

For this size of bar the deflection at first yield, for a windage check, is $7.15 \mathrm{~mm}$ at a load $Q$ of $21 \mathrm{kN}$.

The number of cycles to failure is about 250 at $3.5 \%$ strain and about 80 at double this value when the building deflects to the stops.

Use of the curves indicates that, if the depth of the crawl space is reduced locally, smaller diameters of bar could be used, although the number would need to be increased to provide the required damping force.

\section{TABLE 1}

\section{RESULTS OF TESTS}

N.B. Results in chronological order. Applied deformation in plane of bend unless otherwise stated.

\begin{tabular}{|c|c|c|c|c|c|c|c|c|c|}
\hline $\begin{array}{l}\text { Bar } \\
\text { Dia. } \\
\text { mm }\end{array}$ & $\begin{array}{l}\text { Stroke } \\
(\mathrm{mm})\end{array}$ & $\begin{array}{l}\mathrm{Q}_{d} \\
(\mathrm{kN})\end{array}$ & $\begin{array}{c}\mathrm{fp} \\
(\mathrm{MPa})\end{array}$ & $\begin{array}{c}\text { Cycles } \\
\text { to } \\
\text { failure }\end{array}$ & $\begin{array}{l}Q_{\max } \\
(\mathrm{kN})\end{array}$ & $\frac{Q \max -Q_{d}}{Q_{d}}$ & $\begin{array}{l}\mathrm{k}_{\mathrm{d} / \mathrm{Q}} \mathrm{d} \\
\left(\mathrm{m}^{-1}\right)\end{array}$ & $\begin{array}{c}\text { Estimated } \\
\text { Strain } \\
\text { Range } \\
\text { 음 } \\
\end{array}$ & Remarks \\
\hline 25.4 & 146 & & - & 70 & - & - & & 6.3 & \\
\hline 38.1 & 145 & & - & 35 & - & - & & 9.5 & \\
\hline 25.4 & 146 & & - & 40 & - & - & & 6.3 & $\begin{array}{l}\text { Nylon inserts } \\
\text { at fixities }\end{array}$ \\
\hline 25.4 & 150 & 4.56 & 396 & 180 & 6.82 & 49.6 & 6.6 & 6.3 & $\begin{array}{l}\text { Test at } 90^{\circ} \text { to } \\
\text { plane of bend }\end{array}$ \\
\hline 11.9 & 150 & & - & 290 & - & - & & 3.2 & \\
\hline 15.9 & 150 & & - & 296 & - & - & & 3.9 & \\
\hline 19.1 & 146 & & & 127 & - & - & & 4.7 & \\
\hline 22.2 & 152 & 1.63 & 265 & 100 & 2.10 & 28.6 & 3.8 & 5.5 & \\
\hline 25.4 & 150 & 4.23 & 369 & 60 & 5.51 & 30.3 & 4.0 & $6.3^{*}$ & \\
\hline 25.4 & 148 & 4.83 & 421 & - & 6.57 & 36.0 & 4.8 & 6.3 & $\begin{array}{l}\text { Test at } 45^{\circ} \text { to } \\
\text { plane of bend. } \\
\text { Weld fractured } \\
\text { after } 10 \text { cycles. }\end{array}$ \\
\hline 25.4 & 150 & 5.17 & 451 & 66 & 5.73 & 10.7 & 1.4 & 6.3 & $\begin{array}{l}\text { Bar with a } \\
\text { complete turn } \\
\text { at its centre. }\end{array}$ \\
\hline 31.8 & 149 & 9.88 & 441 & 65 & 13.16 & 33.2 & 4.4 & 7.9 & \\
\hline 38.1 & 147 & 18.54 & 463 & 40 & 22.11 & 19.3 & 2.6 & 9.5 & \\
\hline
\end{tabular}



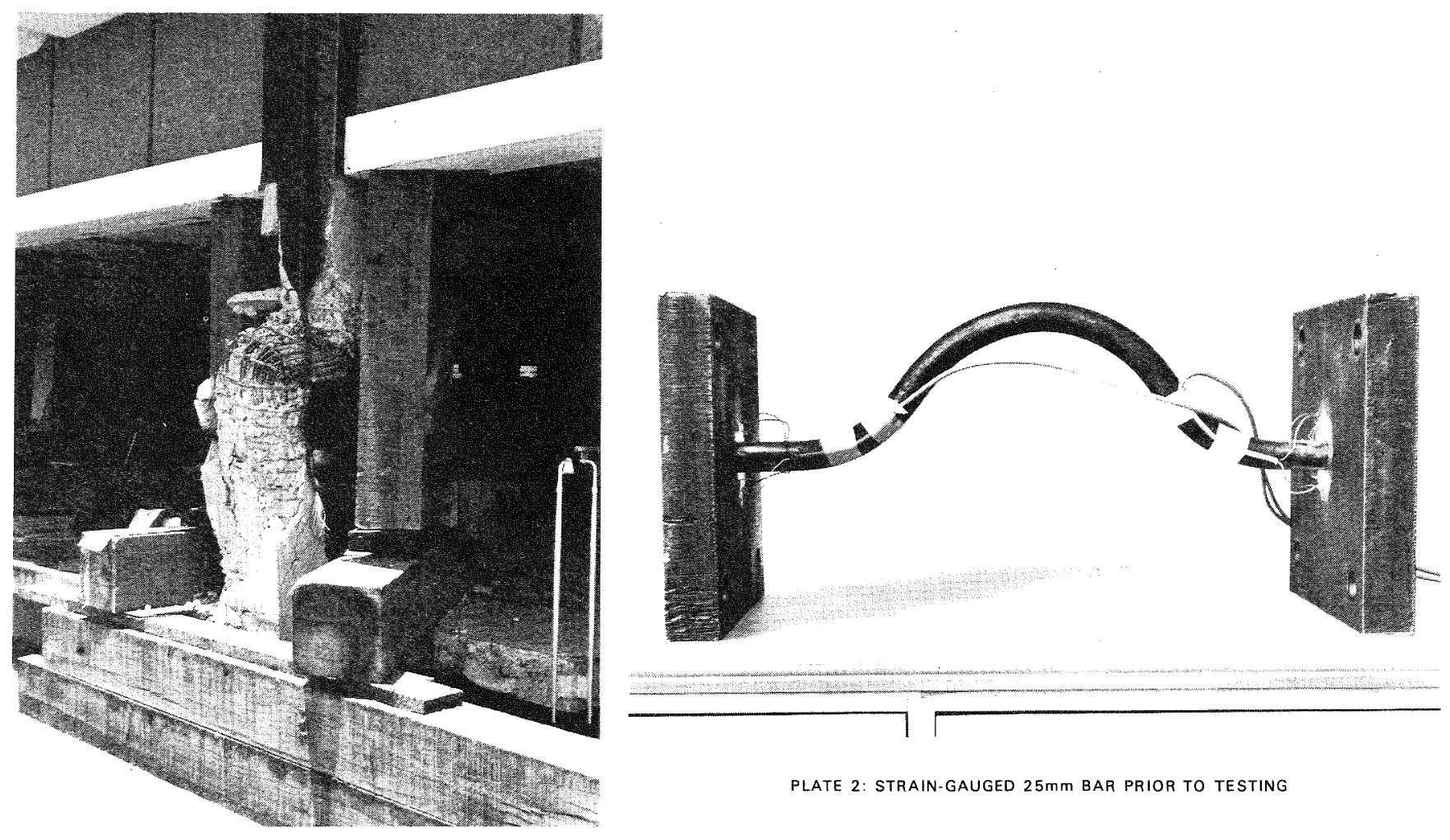

PLATE 1: FAILED COLUMN - PHILIPPINE BAR ASSOCIATION BUILDING, MANILA 1968
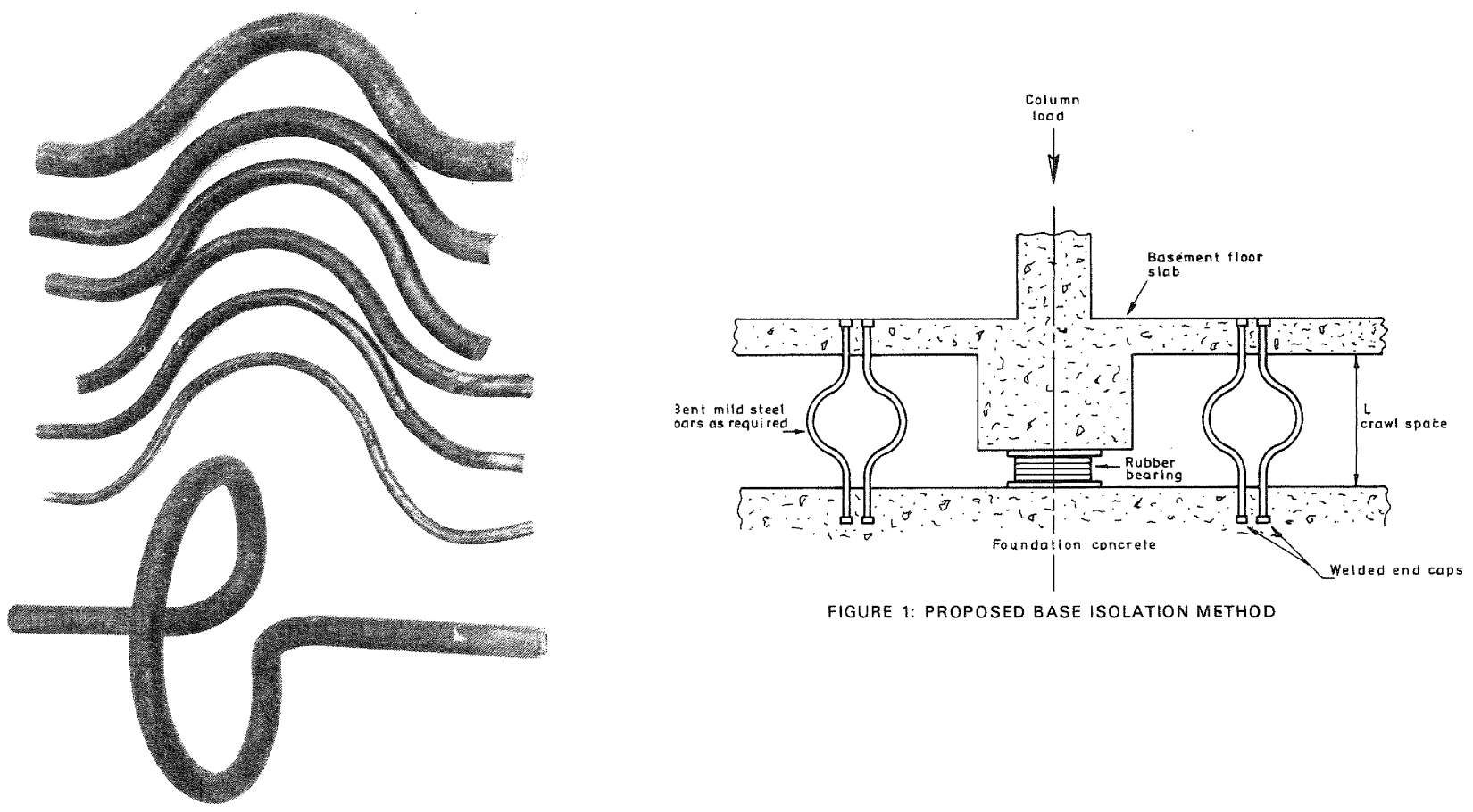

FIGURE 1: PROPOSED BASE ISOLATION METHOD 


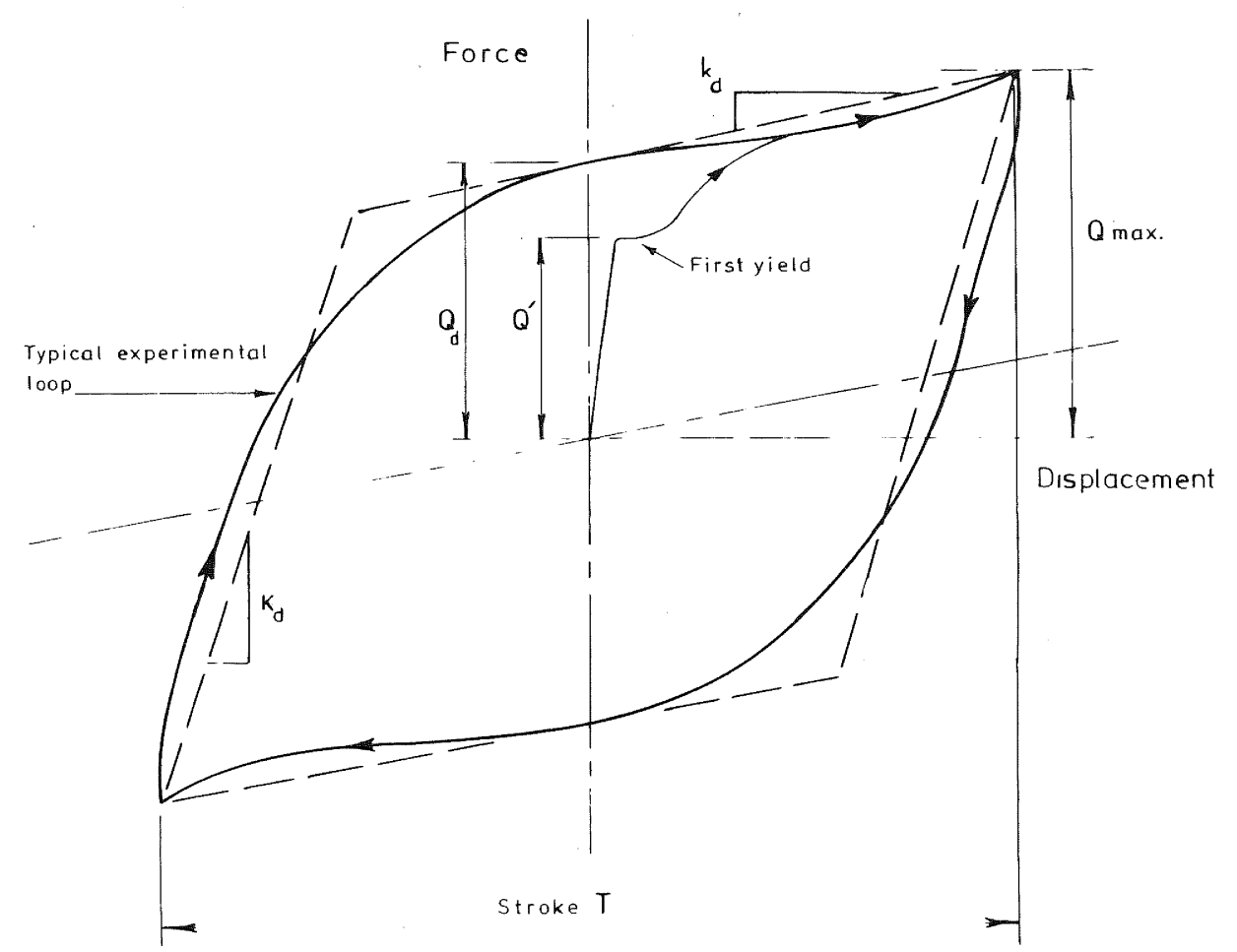

FIGURE 2: LOOP PARAMETERS

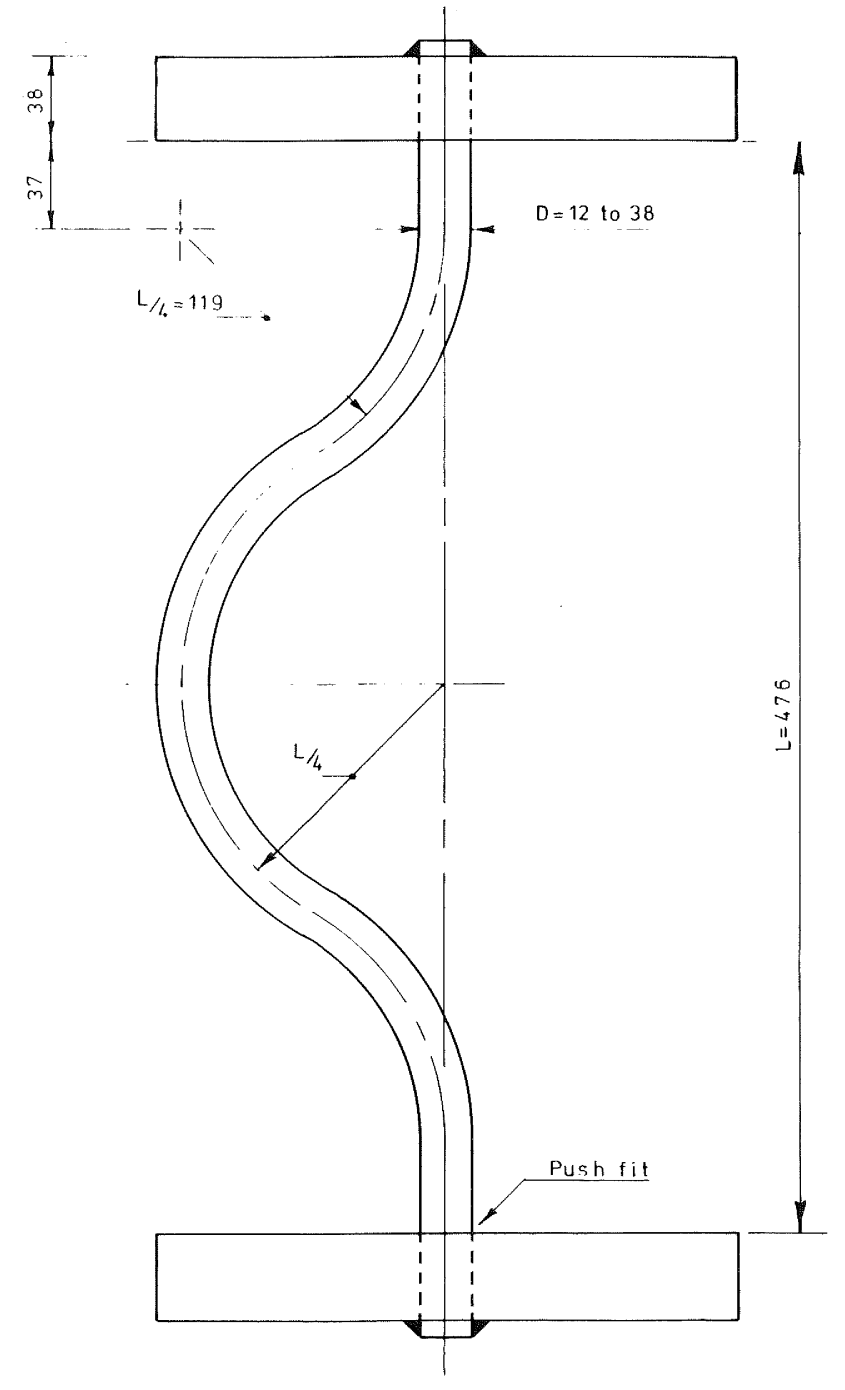

FIGURE 3: PROPORTIONS OF BARS TESTED

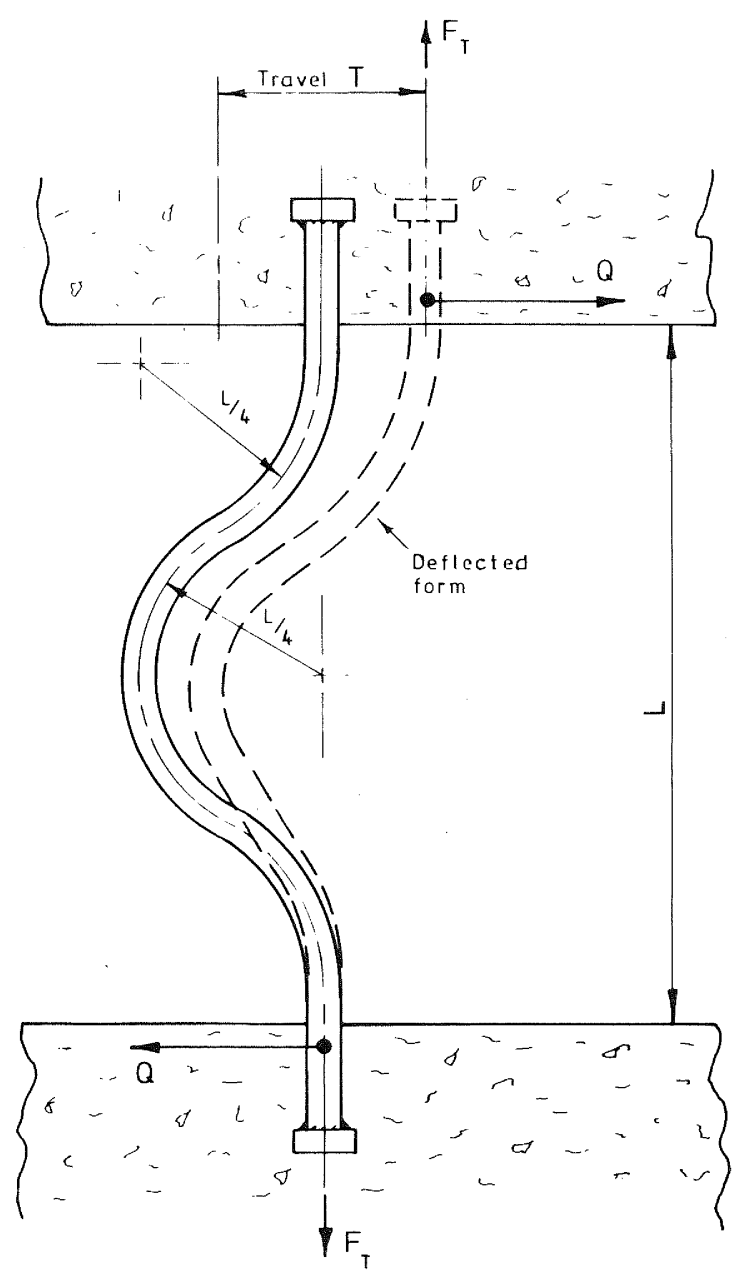

FIGURE 4: FORCES ON BAR 


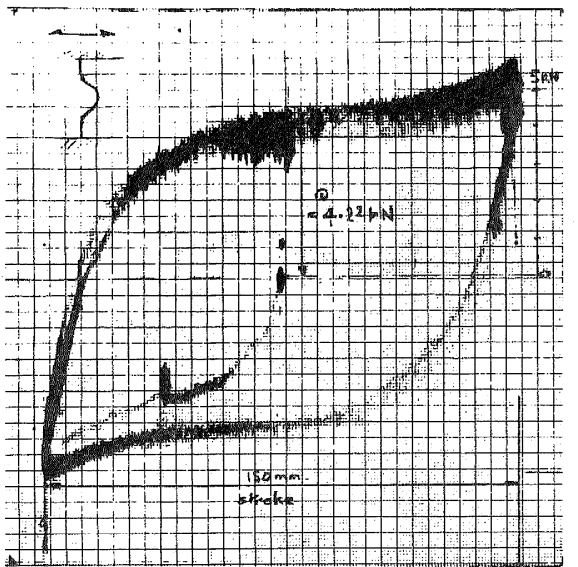

(a) Strain gauge test

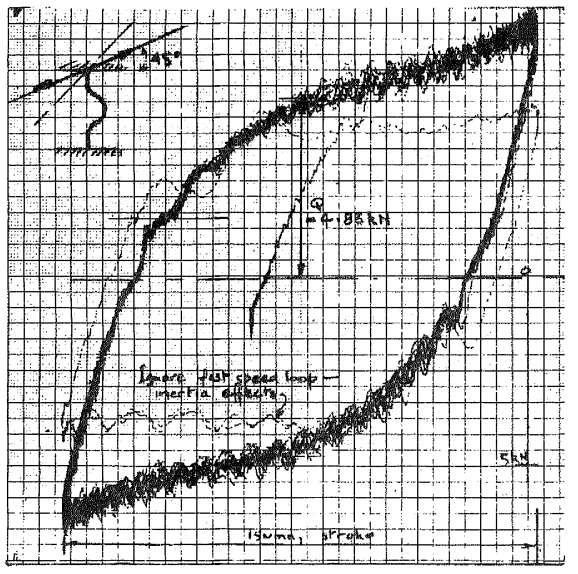

(c) Movement at $45^{\circ}$ to

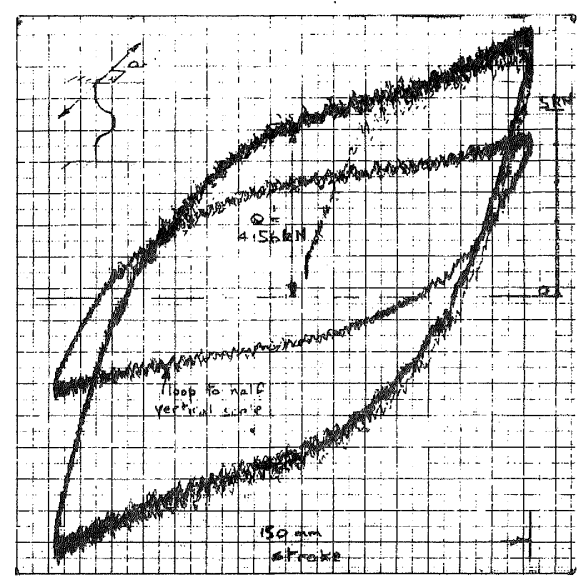

(b) Movement at right angles
to plane of bend

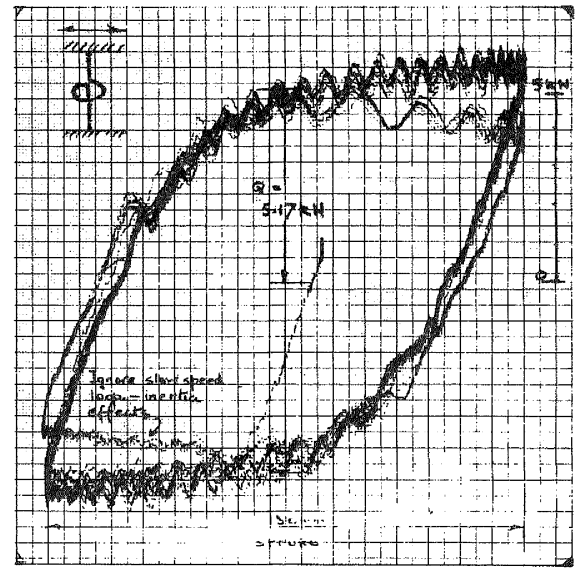

(d) Movement for bar with
complete turn at centre (See plate 3 )

FIGURE 5a: LOAD-DEFORMATION LOOPS FOR $25 \mathrm{~mm}$ BARS

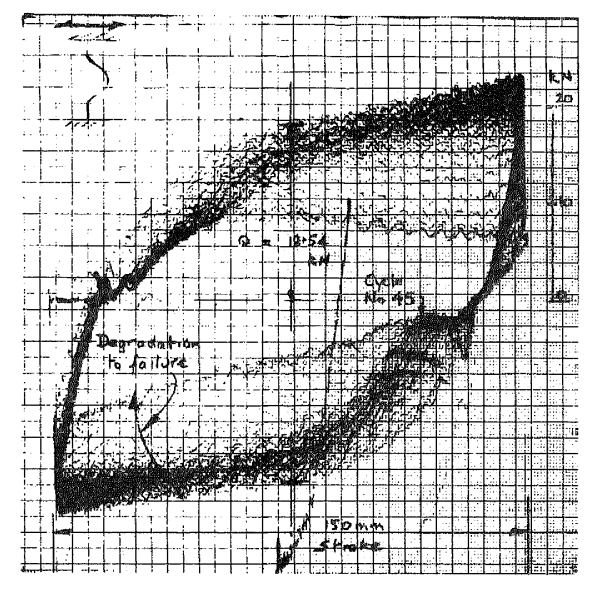

(a) $38 \mathrm{~mm}$ bar

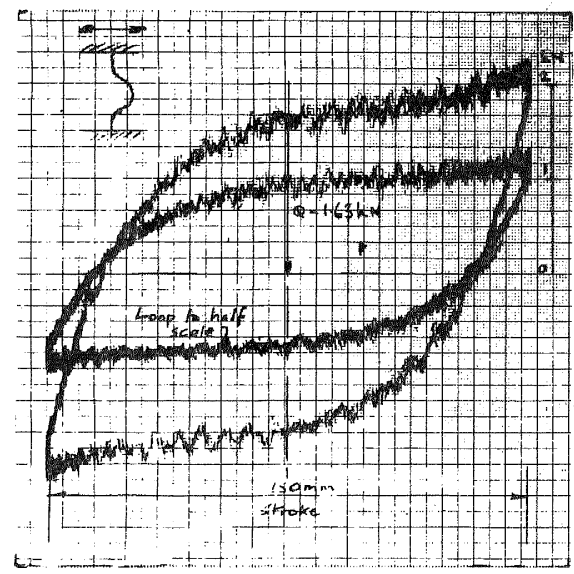

(c) $22 \mathrm{~mm}$ bar

FIGURE 5b: LOAD-DEFORMATION LOOPS FOR VARIOUS BAR SIZES

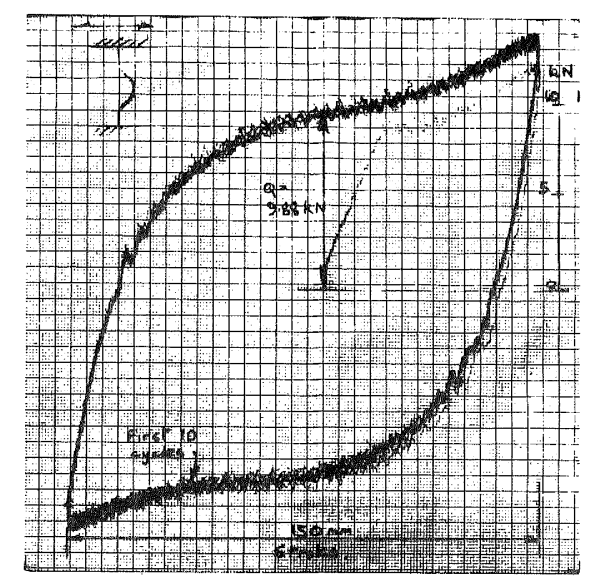

(b) $32 \mathrm{~mm}$ bor

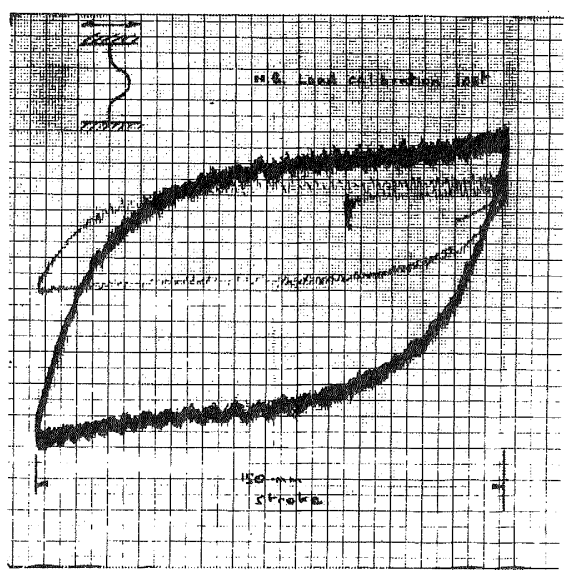

(d) $19 \mathrm{~mm}$ bar 


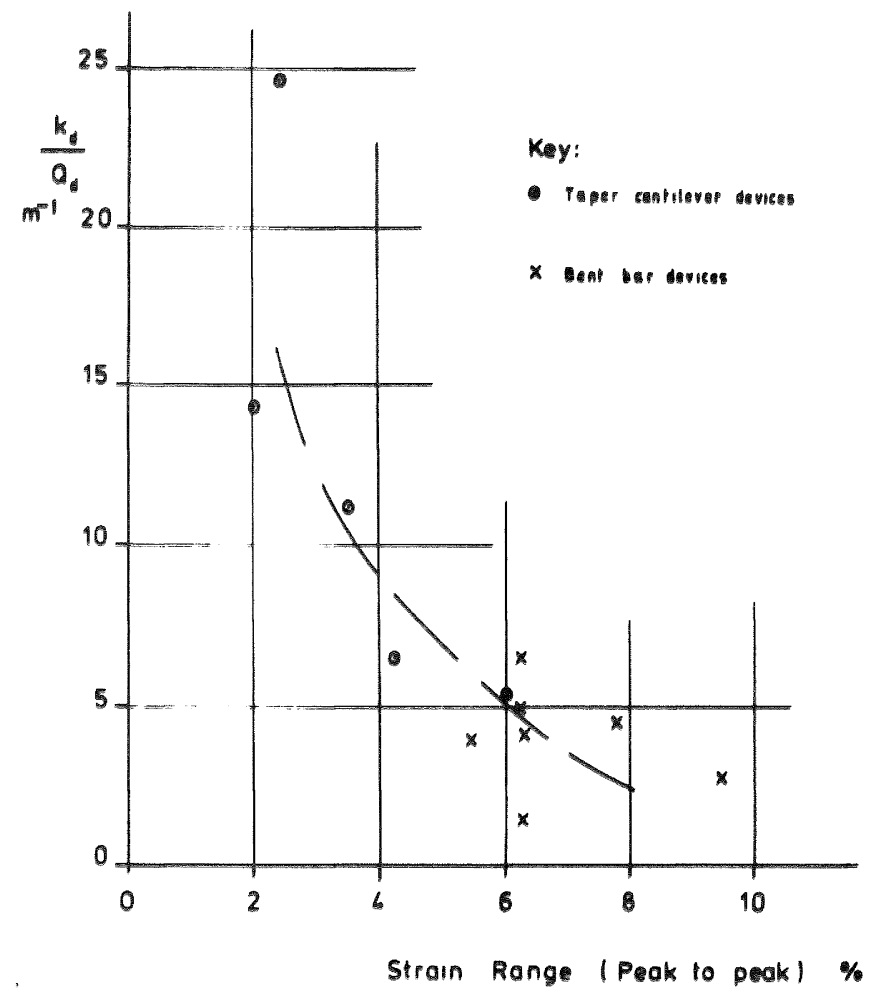

FIGURE 6: STIFFNES Kd/Qd RELATED TO STRAIN

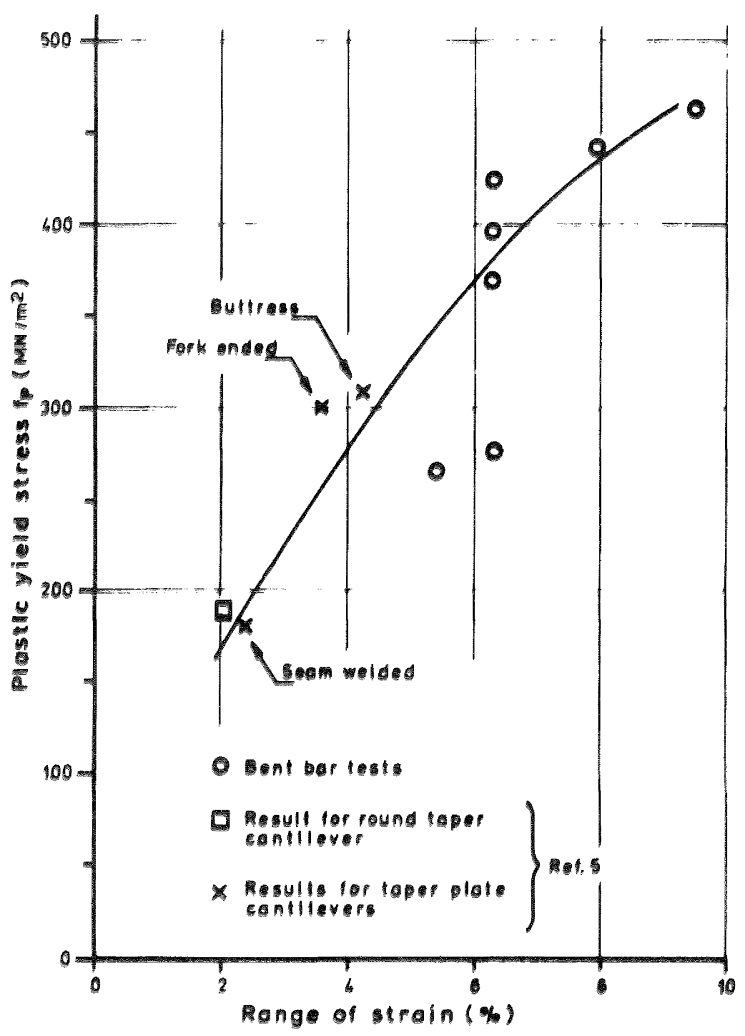

FIGURE 8: PLASTIC YIELD STRESS $f_{p}$ RELATED TO STRAIN LEVEL

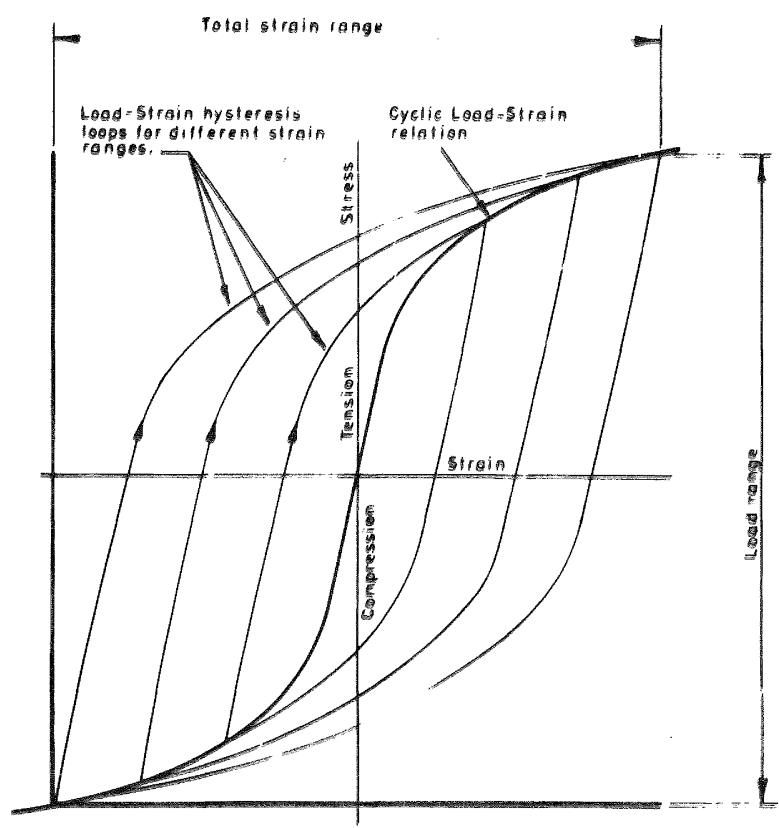

FIGURE 7: FAMILY OF STRESS STRAIN HYSTERESIS LOOPS 


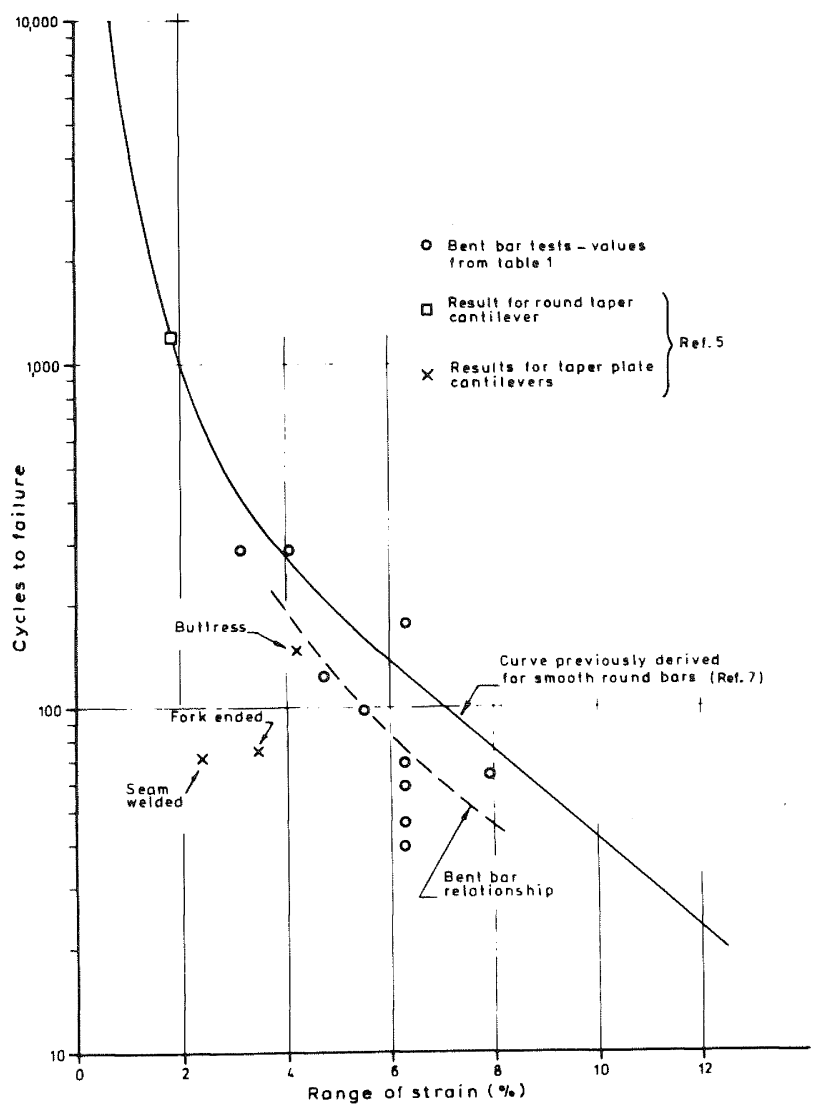

FIGURE 9: FATIGUE LIFE

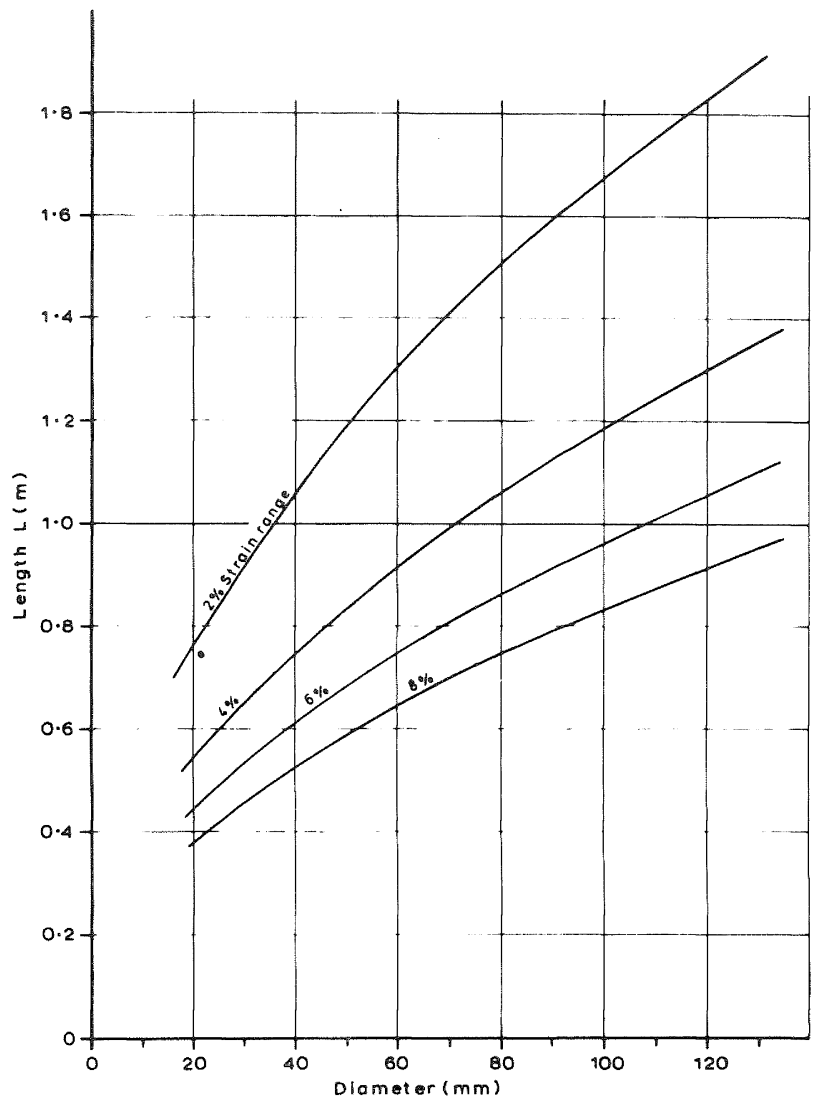

FIGURE 10: LENGTH RELATED TO DIAMETER OF BAR AND STRAIN LEVEL FOR $\pm 75 \mathrm{~mm}$ DEFLECTION

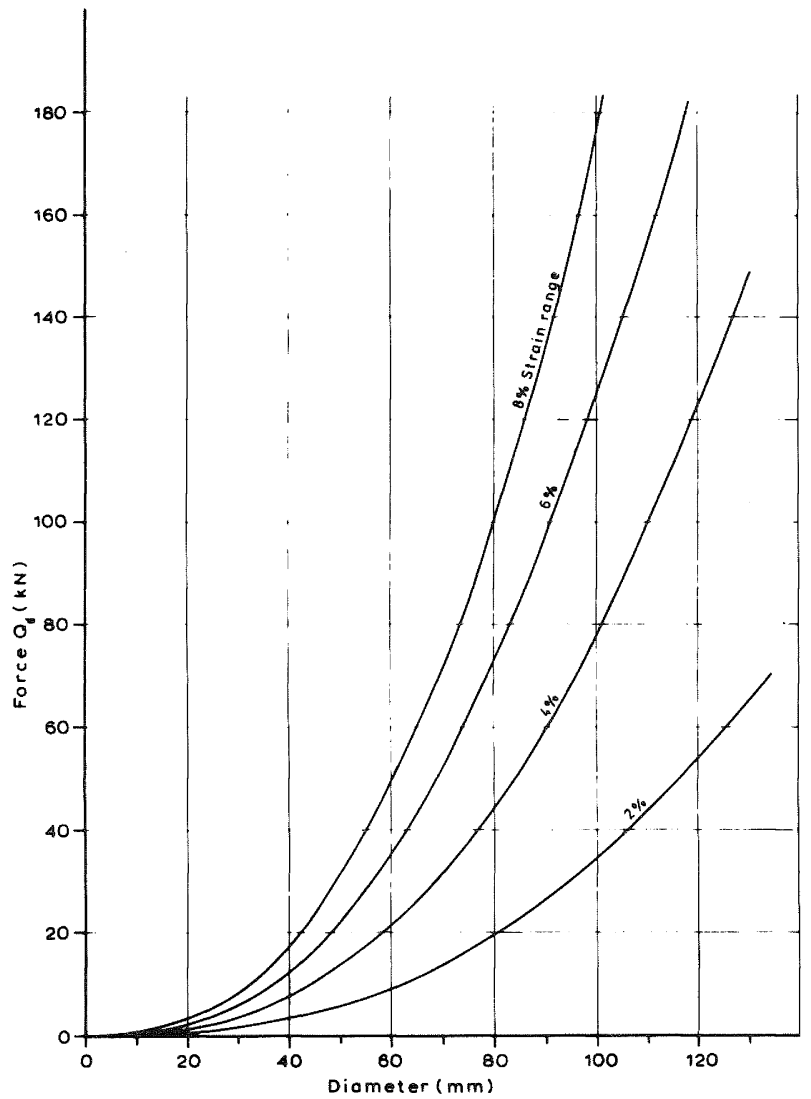

FIGURE 11: FORCE Od RELATED TO 